\title{
Falls from heights: a childhood epidemic in an urban area
}

\author{
Lawrence Bergner, Shirley Mayer, David Harris
}

These two papers are the third and fourth in a series of Injury Classics. Our goal is to reprint one, or occasionally two, such papers in each issue to initiate newcomers to the field of these old, often quoted, and important contributions. As many are difficult to find, it should help all of us to have a copy at hand. Your suggestions about future articles are welcome. Write to the editor with details of your favourite, most quoted paper.
Dr Bergner, Assistant Commissioner for Research and Professional Training; Dr Mayer, Director, Bureau of Child Health; and Dr Harris, Deputy Commissioner, City Health Department (125 Worth Street), New York, NY 10013.

This paper was presented before the Maternal and Child Health Section of the American Public Health Association at the Ninety Seventh Annual Meeting in Philadelphia, PA,

November 11, 1969.

This paper first appeared in the American fournal of Public Health (1971; 61: 90-6) and is reproduced by kind permission of the American Public Health Association.
During the period fanuary 1965-September 1969, there were 201 deaths due to falls from high places among children under 15 years of age in New York City. Alteration of the environment is seen as the most likely means for effective prevention. The proposed program of the Health Department is described.

\section{Introduction}

In July of 1967 the Bureau of Health Statistics of the New York City Department of Health alerted the Commissioner to the existence of an outbreak of fatalities among children due to falls from one level to another. A campaign to alert parents to the risks of such accidents was initiated. Information on methods of prevention was distributed in areas of high risk. At the same time the experience of previous years was reviewed, including data from death certificates and the records of the Medical Examiner. This study of mortality data has continued to the present time and provides the background for the present report and the impetus for an attempt to study similar accidents that do not result in death.

\section{Background}

Accidents are the leading cause of death in children between 1 and 15 years of age in the United States. Four per cent of these deaths are attributed to falls of all kinds. ${ }^{1}$ Most studies of accidents have grouped all falls under one rubric. As such they account for as much as one half of childhood injuries seen in emergency rooms. ${ }^{2}$ Falls from one level to another were indicated as the cause of $19 \%$ of reported accidents in a community survey in New Bedford, Massachusetts, but this apparently included infants falling from furniture, dressing tables, and the like. ${ }^{3}$ In a survey of the 17141 children brought to the emergency department of a large pediatric hospital in Toronto, 5682 were classified as having been due to falls. Of these, there were 587 on or down stairs; 130 from fences, walls, and trees; and 122 from roofs, windows, and balconies. ${ }^{4}$ Among a series of 400 children who had been admitted to the General Hospital, Newcastle upon Tyne, with a head injury, 149 had fallen from a height and five of these died. ${ }^{5}$

Areas with predominantly one and two story construction are unlikely to have a significant injury problem due to this cause. The problem of fatalities may not appear until construction of more than four or five stories is common.
The director of pediatric surgery at a large Cleveland hospital estimated (undocumented) that, of the 6000 children with accidents seen each year in the emergency room, only five to eight were in this category. ${ }^{6} \mathrm{~A}$ British consultant pediatrician has estimated that approximately 1000 children a year in England suffer a fall from a height of greater than one story. The mortality appears to be $1 \%$ or less. About $25 \%$ of the children seen at the hospital $x$ ray department have sustained a fracture of a limb bone or skull. ${ }^{7}$

\section{The New York City data}

During the period January 1965, through September 1969, there were 201 deaths due to falls from one level to another among children under 15 years of age in New York City. For this report, the category includes falls of approximately one story or more - such as falls from windows, fire escapes, and rooftops and excludes falls from tabletops, cribs, and other home furnishings. This represents $12 \%$ of all accidental deaths in this age group. In the 0-4 year group there were 132 such deaths, $16 \%$ of the accidental deaths. In 1967, when there were 61 such deaths, this category accounts for $19 \%$ of the accidental deaths to age 15 and $26 \%$ of those under 5 years of age. Thus these falls rank among the leading causes of accidental deaths of children in New York City.

The age distribution of the fatal cases is clustered in the 1 to 5 year range with the peak between 2 and 3 years. Throughout the age range to 14 years, there is a greater than $2: 1$ excess of males (138 cases) but the sex ratio is less marked among the younger cases. This corresponds to the sex distribution of all accidents in children as described in a community survey ${ }^{3}$ and the national data for deaths due to falls from one level to another. ${ }^{8}$

The fatal falls were not evenly distributed throughout the city. The Bronx with $34 \%$ of the cases and $19 \%$ of the children, and Manhat$\tan$ with $27 \%$ of the cases and $18 \%$ of the children, were overrepresented. When the falls occurred in or about the home $(68 \%$ of the cases) their distribution within the boroughs corresponded to areas of high concentration of dilapidated housing, low income, and other social problems. A preliminary tabulation by hospital of death indicated that $50 \%$ of all cases were seen at four hospitals in the Bronx. This proved to be an artifact resulting from the number of cases not reaching the hospital and the pattern of emergency service which funnels 
Table 1 Deaths of children from falls from heights by year and age, New York City, 1965-1969

\begin{tabular}{lrrrrrrr}
\hline & 1965 & 1966 & 1967 & 1968 & $1969^{*}$ & \multicolumn{2}{c}{ Totals } \\
\hline Under 5 years & 18 & 29 & 47 & 21 & 17 & 132 & $(66 \%)$ \\
5-9 years & 8 & 14 & 10 & 8 & 8 & 55 & $(27 \%)$ \\
10-14 years & 4 & 7 & 4 & 3 & 3 & 14 & $(7 \%)$ \\
Totals & 30 & 50 & 61 & 32 & 28 & 201 & \\
\hline
\end{tabular}

^Through September 30.

Table 2 Deaths of children from falls from heights by sex and age, New York City, 1965-1969

\begin{tabular}{|c|c|c|c|c|c|c|c|c|}
\hline \multirow[b]{2}{*}{ Sex } & \multicolumn{2}{|c|}{$0-4$ years } & \multicolumn{2}{|c|}{ 5-9 years } & \multicolumn{2}{|c|}{$10-14$ years } & \multicolumn{2}{|c|}{$0-14$ years } \\
\hline & No & $\%$ & No & $\%$ & No & $\%$ & No & $\%$ \\
\hline $\begin{array}{l}\text { Male } \\
\text { Female }\end{array}$ & $\begin{array}{l}76 \\
56\end{array}$ & $\begin{array}{l}57 \\
43\end{array}$ & $\begin{array}{r}50 \\
5\end{array}$ & $\begin{array}{l}90 \\
10\end{array}$ & $\begin{array}{r}12 \\
2\end{array}$ & $\begin{array}{l}86 \\
14\end{array}$ & $\begin{array}{r}138 \\
63\end{array}$ & $\begin{array}{l}69 \\
31\end{array}$ \\
\hline Totals & 132 & 100 & 55 & 100 & 14 & 100 & 201 & 100 \\
\hline
\end{tabular}

Table 3 Deaths of children (age 0-14) from falls from heights by borough of residence and population, New York City, 1965-1969

\begin{tabular}{lccccc}
\hline & $\begin{array}{l}\text { Cases of } \\
\text { fatal falls } \\
1965-1969\end{array}$ & & & \multicolumn{2}{l}{$\begin{array}{l}\text { Distribution } \\
\text { of children } \\
\text { 1960 census }\end{array}$} \\
\cline { 2 - 3 } \cline { 5 - 6 } Borough & No & $\%$ & & No & $\%$ \\
\hline Bronx & 69 & 34 & & 344000 & 18 \\
Brooklyn & 70 & 34 & & 674000 & 36 \\
Manhattan & 56 & 28 & & 335000 & 18 \\
Queens & 4 & 2 & & 438000 & 24 \\
Staten Island & 2 & 1 & & 67000 & 4 \\
Totals & 201 & 99 & & 1858000 & 100 \\
\hline
\end{tabular}

Table 4 Deaths of children from falls from heights by site of occurrence and age, New York City, 1965-1969

\begin{tabular}{lrrrrr}
\hline & \multicolumn{2}{c}{ Under 5 years } & & \multicolumn{2}{c}{$0-14$ years } \\
\cline { 2 - 3 } \cline { 6 - 7 } Site & $N o$ & $\%$ & & No & $\%$ \\
\hline Window & 113 & 85 & & 123 & 61 \\
Fire escape & 5 & 4 & 10 & 5 \\
Roof & 1 & 1 & 18 & 9 \\
Stairs & 1 & 1 & 2 & 1 \\
Other & -12 & -9 & & 20 & 10 \\
Unspecified & 12 & 9 & & 28 & 14 \\
Totals & 132 & 100 & & 201 & 100 \\
\hline
\end{tabular}

cases to only four hospitals in the Bronx and many hospitals in other boroughs.

The most striking epidemiologic characteristic of this problem is its seasonal distribution. The cases are limited almost exclusively to the period from the end of May to mid-September. During the period of June through August these deaths account for $29 \%$ of the accidental deaths in ages $0-14$ and $42 \%$ of the accidental deaths in the $0-4$ group. In the younger group this clearly exceeds the fatalities due to the more publicized causes: fire, poisoning, motor vehicle, and drowning.

The specific site from which the fall occurred does not always appear on the death certificate or Medical Examiner's report. In the 201 cases, windows were identified as the specific site in 123 cases. Fire escapes accounted for 10, roofs 18 , and stairs for two cases. Twenty cases were from other sites and, in 28 , the site was not specified.

When analyzed by age and sex it was noted that $90 \%$ of the children under 5 years had fallen from windows and fire escapes. Children 5 and older (predominantly boys) fell from diverse locations outside the home such as rooftops, air and elevator shafts, stairwells, rock piles, and construction sites, reflecting the tendency of boys to be in play situations in these areas.

\section{Fatal and non-fatal outcome}

There is a modest body of knowledge concerning the influence of physical factors on severity of injury. The distance fallen is not the absolute determinant. Extent of injury and likelihood of survival are dependent upon the position of the body at impact and the material impacted. There are recorded cases of persons having survived falls of 1000 feet. ${ }^{9}$ Twenty two of 53 persons who fell or jumped from a height of three or more stories (approximately $35 \mathrm{feet}$ ) onto concrete in one district of New York City survived. ${ }^{10}$ In the summer of 1968 two pediatric neurology residents at municipal hospitals in the Bronx, who had seen five fatal cases and two cases with serious sequelae within a short period of time, were able to uncover the records of 55 non-fatal cases hospitalized in the period 1966-1968. ${ }^{11}$ Their immediate practical interest was in the events that followed the fall - what factors influenced the severity of injury and what medical and surgical procedures could influence the ultimate outcome. From the Health Department's viewpoint, however, once the fall has been initiated the outcome is a matter of chance.

\section{Study of non-fatal cases}

Fatal falls were clearly only a part of the problem and the interest of clinical colleagues presented an opportunity for the Health Department to begin to study the many nonfatal falls from one level to another.

In order to investigate the possibilities for prevention, it was decided to focus upon the circumstances surrounding the fall. With the help of the two hospital residents (and their chief consultant), arrangements were made for the Health Department to be notified of cases of falls from heights of more than 10 feet, seen at the four hospitals in the Bronx most likely to receive such cases. The listing of fatal cases was compiled by the Bureau of Health Statistics.

An interview schedule was designed to obtain information on the child's personal history, family constellation, utilization of community health facilities, circumstances surrounding the accident, actual physical environment from which the fall occurred, and potential for prevention.

A recent graduate with a masters in social work attempted the interviews with parents of cases reported from the hospitals. Families in which a child had died were assigned to a more experienced social worker with the Department of Health. 


\section{Results}

Twenty two reports of non-fatal falls were received from the four hospitals in the Bronx during the period from June 9 to August 15, 1969; an additional 14 children died after falls. Of the 22 non-fatal cases reported, 17 were found to meet the minimum distance criterion of 10 feet. Successful interviews were obtained with nine families of non-fatal cases and six families in which deaths resulted. Although only 15 families were interviewed, all 31 families lived within the welfare-poverty district of the Bronx, and it is assumed that they share the problems of poverty common to the families interviewed.

While the small number of interviews in this pilot study does not allow elaborate statistical analysis, the cases are sufficiently uniform to provide a profile of a fall victim and his family. $\mathrm{He}$ is likely to be a preschool male in good health (according to his mother), with no serious illnesses or accidents in the past. He has had minimal preventive medical care, usually immunization shots only. Compared to other children, he is judged by his mother to be more active and liked rough types of play, although it is not thought likely that he would get hurt more often than other children.

The victim's family is usually composed of seven members; the fall victim is most often a 'middle' child among six children. There is no father in the home. The mother receives a check from the Welfare Department of approximately $\$ 50$ to $\$ 75$ per week. The mother, herself, takes care of the children in the home, but it is very likely she has other children in foster care. Her own health is reported to be fair or poor. She does not use any family planning method (only four in 15 mothers utilized or indicated that they would like to avail themselves of this information). Other members of the family have had injuries due to accidents in the past year. There is about a one-in-three chance of mental illness in the family. Contrary to the stereotype that welfare families are transient, most of these families have been in their present housing situation for four years or more.

The rent spent for a four or five room walk-up apartment with its own kitchen and bathroom (often not functional) is from $\$ 50$ to $\$ 100$ per month. In these apartments there are many holes in the ceilings and walls, loose parts in the floor, broken windows, plumbing leaks, inadequate lighting, rats and other vermin. The fall victim usually does not have his own room or his own bed. If over 5 years of age, he plays in the streets.

Most of the persons interviewed said that the only thing the victim had done 'wrong' preceding the accident was to climb to the site of the fall (be it a window, fire escape, or the like). In most of these falls the child had been 'playing' either in the window or on the fire escape, and fell.

\section{Discussion}

Studies of the circumstances surrounding various kinds of childhood accidents have called attention to the occurrence of acutely stressful events such as family illness, shifts in supervision, change in residence, and so on, that reduced the protective forces in the child's immediate environment. Chronic stress related to family disorganization and inadequate supervisory arrangements have also been implicated. ${ }^{12}$ Although the familes in this series had many serious social problems that may have been involved in the sequence of events leading to a fall, the most obvious factor and perhaps the one most susceptible to significant manipulation is the immediate physical environment.

Unguarded windows were the primary source of danger from falls. The window frames in these dwellings were observed to be unlikely to support a window guard properly. Moreover, the cost of guards currently acceptable in the Fire Department and the New York City Board of Standards and Appeals for the type of window (double-sash and approximately two feet from floor to sill) in an average apartment of a tenement such as those observed, would cost approximately $\$ 115$ per unit. Each apartment has five to six windows. The fire escape window guard requires a lock device - at a cost of $\$ 53$ - that offers protection against burglars but assures occupants and firemen access to the fire escape; its primary purpose is not child safety. The other windows can be permanently barred by a series of horizontal metal bands costing $\$ 15$ per window.

It is noteworthy that, in the public housing projects in the Bronx during the period of this study, not one such fall was reported. Some of the reasons for this, as given by the chief of the Management Division of the Housing Authority, included (1) fireproof construction eliminating need for exterior fire escapes; (2) windows in newer buildings of the casement type, and many of the double-sash windows with gates (inside or out) or locking devices that can adjust a window to whatever height desired; and (3) play areas with permanently installed toys so that preschool children have climbing opportunities outdoors.

\section{Implications}

The public health education program concerning prevention of falls will continue. Emerging from this study are indications for several additional approaches by the Department of Health:

First - Since $66 \%$ of the falls are incurred by children under 5 years and unguarded windows are the primary site from which they fall, the Department of Health, through its Environmental Health Services, has undertaken to develop, with the Fire Department, a less expensive window guard. The Health Department will also promote a change in the multiple dwelling law to mandate window guards in apartments housing young children. Furthermore, it will explore with Model Cities groups their interest in contracting for installation of window guards by people trained within the community. 
Second - Child abuse or purposeful neglect cannot be eliminated from consideration as a contributing factor even when the case has been cleared by the Medical Examiner's office. The Department of Health will work with the Medical Examiner's office to require full postmortems and full body $x$ rays of all children sustaining falls from heights. Furthermore, the names of all families experiencing this type of accident will be checked against the Child Abuse Registry maintained by the Bureau of Protective Services, in an effort to prevent similar episodes among siblings.

Third - Long-range sequelae such as mental retardation or other chronically handicapping conditions in children who survive their falls have not been followed, nor is there a reporting mechanism to facilitate this. Reporting is also the first essential step toward putting these families in touch with a social agency through which help in child care, such as arrangements for day care service, might be obtained. The department is therefore exploring methods of obtaining notification of these cases on a voluntary or a mandatory basis.

Fourth - Further attempts will be made to discover whether the children of certain families within the areas where those accidents occur are at particularly high risk of experiencing a fall from a high place.

\section{Summary}

Falls from high places - primarily from windows - are among the leading causes of accidental death of children in New York City. Cases occur almost exclusively in the summer months and are clustered in the 1 to 5 year age range with the peak between 2 and 3 years. Two thirds of the fatalities are among boys.

The cases are concentrated in areas of dilapidated housing, low income, and other social problems. Visits to the homes of nonfatal and fatal cases revealed an absence of environmental protection.

The Health Department plans to increase primary prevention efforts by continuing an education campaign and undertaking to insure the provision of environmental protection devices. It will also institute steps to mitigate the sequelae of non-fatal falls by developing a reporting system and bringing the children to the attention of the appropriate medical and social agencies.

The authors are indebted to Miss Susan Griffiths and Mis Jenness Eertmoed and the staff of the Bureau of Public Health Social Work for the field work undertaken in difficult circumstances. Mrs Frieda Nelson provided the special tabulations of death certificate information.

Mr Frederick Kent, associate deputy commissioner of Environmental Health Serives, contributed to the analysis of the Environment action.

1 Accident facts. Chicago: National Safety Council, 1969.

2 Izant RJ, Hubay CA. The annual injury of 15000000 children: a limited study of childhood accidental injury and death. F Trauma 1966; 6: 65-74.

3 Rice RG, Starbuck GW, Reed RB. Accidental injuries to children. $N$ Engl 7 Med 1956; 255: $1212-9$.

4 Keddy JA. Accidents in childhood: a report on 17141 accidents. Can Med Assoc f 1964; 91: 675-80.

5 Rowbotham GF, Maciver IN, Dickson J, Bousfield ME. Analysis of 1400 cases of acute injury to the head. $B M \mathcal{F}$ 1954; i: $726-30$

6 Izant RJ. Personal communication. April 29, 1969.

Llewellyn KR. Window accidents. Correspondence. $B M$ 1968; i: 444, and personal communication, May 13, 1969.

8 Accidental falls: fatal and non-fatal. Statistical Bulletin of the Metropolitan Life Insurance Co 1965; 46: No 4 (Aug)

9 Snyder RG. Human tolerances to extreme impacts in free-fall. Aerospace Med 1963; 34: 695-709.

10 Lewis WS, Lee AB, Grantham SA. 'Jumpers syndrome' The trauma of high free fall as seen at Harlem Hospital. $\mathcal{f}$ Trauma 1965; 5: 812-8.

11 Sieben RL, Leavitt JD, French JH. The effects of falls from great heights upon children. Pediatrics (to be published in 1971).

12 Meyer RJ, Roelofs HA, Bluestone J, Redmond S. Accident injury to the pre-school child. $\mathcal{F}$ Pediatr 1963; 63: 95-105.
Mr Francis C Lindaman, Director, Office of Professional and Public Health Education, New York City Department of Health, 125 Worth Street, New York, NY 10013. Ms Spiegel, Director, NYC Window Falls Prevention Program. Falls Prevention Program.
This paper, submitted to This paper, submitted to
the Journal December 28, 1976, revised and accepted for publication July 15,1977 , is based on a paper presented af the American Public of the American Public Bealth.

This paper first appeared in the American fournal of Public Health $(1977 ; 67$ $1143-7$ ) and is reproduced by kind permission of the American Public Health Association.

\section{Children can't fly: a program to prevent childhood morbidity and mortality from window falls}

\author{
Charlotte N Spiegel, Francis C Lindaman
}

\begin{abstract}
'Children Can't Fly' is a health education program developed by the New York City Department of Health to combat the high incidence of child mortality and morbidity due to falls from windows. The success of the program, begun in 1972 , in drastically reducing death and injury persuaded the New York City Board of Health to amend the Health Code in 1976
\end{abstract}

to require that landlords provide window guards in apartments where children 10 years old and younger reside. The law is the first and only one of its kind in the nation.

The program has four major components: (1) reporting of falls by hospital emergency rooms and police precincts, followed up by counseling, referral and data collecting by public health nurses; 